\title{
PROFIL KEMAMPUAN PEMBEDAAN RANGKAIAN SERI DAN PARALEL CALON GURU SEKOLAH DASAR
}

\author{
Muhammad Erfan, Mohammad Archi Maulyda, Ida Ermiana, Vivi Rachmatul, Hidayati, \\ dan Tursina Ratu
}

Universitas Mataram

Universitas Samawa

e-mail: $\underline{\text { muhammaderfan@unram.ac.id }}$

\begin{abstract}
Abstrak
Penelitian ini bertujuan untuk mendeskripsikan profil kemampuan calon guru sekolah dasar dalam membedakan rangkaian seri dan rangkaian paralel. Penelitian ini termasuk penelitian kuantitatif dengan pendekatan deskriptif. Sampel diambil secara acak (random sampling) sebanyak 195 orang mahasiswa calon guru sekolah dasar di salah satu universitas negeri di kota Mataram, Nusa Tenggara Barat. Data dikumpulkan melalui tes sebanyak 40 butir soal berbentuk pilihan ganda dengan dua opsi jawaban. Teknik analisis data dilakukan dengan peresentase ketercapaian per indikator dan dikatagorikan berdasarkan kriteria yang ditetapkan.Berdasarkan persentase jawaban mahasiswa pada masing-masing indikator diperoleh bahwa pada besaran satuan rangkaian listrik katagori baik, pada alat ukur listrik katagori cukup, pada susunan rangkaian listrik katagori kurang, pada karakteristik rangkaian berdasarkan arus listrik kategori cukup, pada karakteristik rangkaian berdasarkan tegangan listrik katagori cukup, serta pada karakteristik rangkaian berdasarkan daya listrik adalah katagori cukup. Secara keseluruhan mahasiswa calon guru sekolah dasar cukup mampu membedakan rangkaian seri dan rangkaian paralel.
\end{abstract}

Kata Kunci: Rangkaian Listrik, Seri, Paralel, Calon Guru, Sekolah Dasar

\begin{abstract}
This study aims to identify the ability of prospective elementary school teachers to differentiate series and parallel circuits. This research is quantitative research with a descriptive approach. Samples were taken randomly (random sampling) as many as 195 students prospective elementary school teachers at one of the state universities in Mataram, West Nusa Tenggara. Data were collected through a test of 40 items in the form of multiple-choice questions with two answer options. The data analysis technique is done by the percentage of achievement per indicator and categorized according to the specified criteria. Based on student responses on each indicator obtained on each indicator obtained in the equations of the electrical circuit units in the good category, on the electrical measuring instrument of the category sufficiently, on arrangement of electrical pairs of categories is lacking, on the characteristics of the circuit based on electrical current is sufficient category, on the series of characteristics based on the electrical voltage of the adequate category, and on the characteristics of the circuit based on the electric power is sufficient category. Overall, prospective elementary school teacher candidates of the Mataram University Primary School Teacher Education Study Program are quite able to arrange parallel series and series.
\end{abstract}

Keywords: Electric Circuits, Series, Parallel, Prospective Teacher, Elementary School 


\section{PENDAHULUAN}

IImu Pengetahuan Alam (IPA) atau Sains merupakan mata pelajaran yang tidak hanya dapat diperoleh dengan melihat dan membaca saja tetapi juga dalam konsepkonsepnya selalu berhubungan dengan berbagai fenomena alam dan fakta-fakta nyata yang berkaitan dengan gejala-gejala alam dalam kehidupan sehari-hari (Weisberg, Hopkins, \& Taylor, 2018; Sudarmadji, 2013). Tujuan diberikannya materi IPA untuk peserta didik tingkat sekolah dasar yakni agar peserta didik dapat memahami konsep dasar Sains atau IPA yang kemudian dapat dihubungkan secara kontekstual dalam kehidupan sehari-hari (Erfan, Widodo, Umar, Radiusman, \& Ratu, 2020). Hakikat IPA sebagai produk, proses, dan sikap selalu ditekankan dalam proses pembelajaran IPA agar di dalam proses pembelajaran IPA, peserta didik tidak hanya sekedar duduk manis menerima sekumpulan pengetahuan dari pendidik, tetapi juga berproses melalui serangkaian kegiatan dalam rangka mengembangkan aspek kognitif, afektif, maupun psikomotor melalui rentetan pembelajaran di bangku sekolah (Fajari, Joharman, \& Salimi, 2018; Desstya, 2014; Khishfe, 2012).

Pembelajaran di sekolah dasar sesuai dengan Kurikulum 2013 adalah pembelajaran tematik integratif (Khoeriyah \& Mawardi, 2018). Pembelajaran tematik integratif merupakan pendekatan pembelajaran yang mengintegrasikan berbagai kompetensi dari berbagai mata pelajaran ke dalam berbagai tema sebagai pemersatu kegiatan-kegiatan pembelajaran dalam satu kali tatap muka (Hakim, 2014; Mawardi, 2014). Unit tematik integratif merupakan pembelajaran yang menyentuh semua mata pelajaran dan memperkenalkan salah satu tema sentral yang akan meningkatkan kemampuan belajar anak (Ramdhani \& Yuliastri, 2018).

Salah satu tema pembelajaran tematik integratif yang ada di buku guru maupun buku siswa kelas VI (enam) sekolah dasar adalah tema 3 yaitu Tokoh dan Penemuan. Pada subtema 2 tentang penemuan dan manfaatnya, salah satu kompetensi yang dikembangkan adalah hantaran dan rangkaian listrik pada aspek pengetahuan dan dari berbagai kegiatan yang ada di buku tersebut, pendidik bersama peserta didik samasama membahas tentang rangkaian listrik seri maupun rangkaian paralel (Afriki et al., 2015). Untuk menyikapi hal ini, program studi pendidikan guru sekolah dasar fakultas keguruan dan ilmu pendidikan Universitas Mataram mengikutkan keterampilan membuat rangkaian listrik sederhana di dalam mata kuliah Pendidikan Sains Sekolah Dasar.

Rangkaian listrik dapat dibedakan menjadi rangkaian seri dan rangkaian paralel. Pada rangkaian seri, kuat arus listrik yang mengalir pada masing-masing beban adalah sama (Nurrahmawati, Supeno, \& Prihandono, 2018), jumlah penurunan tegangan pada rangkaian seri dari masing-masing beban seri adalah sama dengan tegangan total pada sumber tegangan, kuat arus yang mengalir pada rangkaian seri tergantung pada jumlah 
besar beban atau tahanan beban dalam rangkaian, serta jika salah satu beban atau bagian dari rangkaian terputus, maka aliran arus akan terhenti. Rangkaian paralel yang dicirikan dengan beda potensial atau tegangan pada masing-masing beban sama dengan tegangan sumber, besar kuat arus pada masing-masing cabang adalah tergantung pada besar hambatan masing-masing cabang, tahanan total pada rangkaian lebih kecil daripada hambatan terkecil, serta jika salah satu cabang rangkaian terputus, maka cabang rangkaian yang lain akan tetap menyala (Manurung \& Sinambela, 2018). Jika dilihat lebih jauh, dapat diketahui bahwa terdapat perbedaan yang fundamental antara rangkaian listrik seri dan rangkaian listrik paralel. Kemampuan mengenali dan membedakan rangkaian seri dan rangkaian paralel inilah yang seharusnya dikuasai oleh calon guru sekolah dasar.

Sejauh ini belum ada penelitian sebelumnya yang mengidentifikasi kemampuan mahasiswa calon guru sekolah dasar dalam mengidentifikasi maupun membedakan rangkaian listrik seri dan rangkaian paralel khususnya di program studi pendidikan guru sekolah dasar fakultas keguruan dan ilmu pendidikan Universitas Mataram. Oleh karena itu dengan adanya identifikasi profil kemampuan membedakan rangkaian seri dan rangkaian paralel mahasiswa calon guru sekolah dasar diharapkan dapat menjadi rujukan maupun masukan bagi berbagai komponen pendidikan khususnya yang ada di program studi pendidikan guru sekolah dasar FKIP Universitas Mataram dalam melangsungkan kegiatan perkuliahan pendidikan sains sekolah dasar.

\section{METODE}

Penelitian ini merupakan penelitian kuantitatif dengan pendekatan deskriptif dan bertujuan untuk mengidentifikasi profil kemampuan mahasiswa calon guru sekolah dasar dalam membedakan rangkaian seri dan rangkaian paralel. Populasi pada penelitian ini berupa seluruh mahasiswa calon guru sekolah dasar yang ada di salah satu universitas negeri di Kota Mataram, Nusa Tenggara Barat. Teknik pengambilan sampel yang digunakan adalah teknik random sampling yang selanjutnya diperoleh jumlah sampel penelitian sebanyak 195 orang mahasiswa.

Data dalam penelitian ini diperoleh dengan teknik tes yang diberikan melalui Google Form. Tes yang dilakukan berupa tes pilihan ganda dengan dua pilihan jawaban sebanyak 40 butir soal yang dibuat berdasarkan indikator kemampuan membedakan rangkaian seri dan rangkaian paralel. Profil kemampuan mahasiswa dalam membedakan rangkaian seri dan rangkaian paralel dilihat berdasarkan persentase mahasiswa yang mampu menjawab butir soal sesuai indikator. Indikator penguasaan kemampuan membedakan rangkaian seri dan rangkaian paralel beserta nomor item pada soal tes disajikan pada Tabel 1. 
Tabel 1. Indikator dan Nomor Soal Kemampuan Membedakan Rangkaian Llstrik

\begin{tabular}{|c|c|c|}
\hline No. & Indikator & Keterangan \\
\hline 1 & $\begin{array}{l}\text { Besaran dan satuan pada rangkaian } \\
\text { listrik }\end{array}$ & $1,2,3,4,5,6,7,8$ \\
\hline 2 & Alat ukur tegangan dan kuat arus listrik & 9,10 \\
\hline 3 & Susunan rangkaian listrik seri dan paralel & 13,14 \\
\hline 4 & Karakteristik arus pada rangkaian listrik & $\begin{array}{l}11,12,15,16,17,18,23,24, \\
27,28,29,30,31,32\end{array}$ \\
\hline 5 & $\begin{array}{l}\text { Karakteristik tegangan pada rangkaian } \\
\text { listrik }\end{array}$ & $\begin{array}{l}19,20,21,22,25,26,33,34, \\
35,36\end{array}$ \\
\hline 6 & Disipasi daya pada rangkaian listrik & $37,38,39,40$ \\
\hline
\end{tabular}

Pengkategorian kemampuan calon guru sekolah dasar dalam membedakan rangkaian seri dan paralel ditentukan dengan kriteria seperti pada Tabel 2.

Tabel 2. Kategori Profil Kemampuan Pembedaan Rangkaian Listrik

\begin{tabular}{ccc}
\hline No. & Persentase & Kategori \\
\hline 1 & $10-40$ & Kurang \\
2 & $41-70$ & Cukup \\
3 & $71-100$ & Baik \\
\hline
\end{tabular}

\section{HASIL DAN PEMBAHASAN}

Hasil kemampuan mahasiswa dalam membedakan rangkaian seri dan rangkaian paralel berdasarkan masing-masing indikator ditunjukkan oleh Gambar 1.

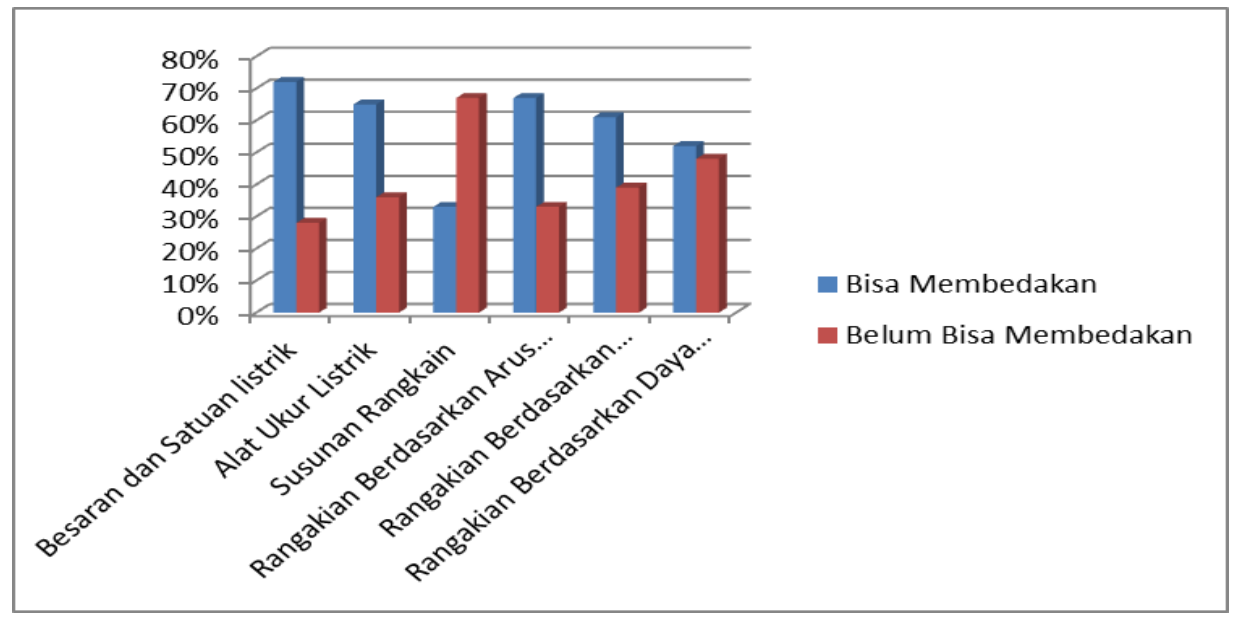

Gambar 1. Persentase Kemampuan Calon Guru Sekolah Dasar dalam Membedakan

Rangkaian Listrik Berdasarkan Masing-Masing Indikator

Berdasarkan Gambar 1 dapat diketahui bahwa indikator pertama yaitu tentang besaran dan satuan pada rangkaian listrik merupakan indikator dengan persentase tertinggi yaitu $72 \%$. Artinya, sebanyak 140 orang dari 195 mahasiswa yang mampu membedakan rangkaian seri dan rangkaian paralel. Sebagian besar soal-soal pada indikator besaran dan satuan menanyakan tentang satuan yang umumnya terdapat dalam mengukur atau 
merancang berbagai rangkaian listrik sederhana dan pastinya selalu ada dalam rangkaian seri maupun rangkaian paralel. Soal termudah pada indikator besaran dan satuan pada rangkaian listrik adalah tentang satuan kuat arus listrik di mana sebanyak 179 (92\%) mahasiswa sudah mampu menjawab dengan benar. Butir soal tersulit pada indikator besaran dan satuan pada rangkaian listrik adalah satuan daya listrik dengan jumlah mahasiswa yang mampu menjawab dengan benar hanya $41 \%$ atau hanya 80 orang dari 195 orang mahasiswa.

Indikator kedua tentang alat ukur tegangan dan kuat arus listrik hanya terdiri dari dua butir soal. Soal pada nomor 9 tentang apakah tensimeter merupakan alat ukur yang benar untuk mengukur tegangan listrik mampu dijawab dengan benar (mahasiswa menyatakan ketidak setujuannya) oleh mahasiswa dengan persentase $86 \%$ atau 168 dari 195 orang total keseluruhan sampel. Sementara soal kedua (nomor 10) yang menanyakan apakah Ammeter merupakan alat untuk mengukur kuat arus listrik hanya mampu dijawab dengan benar oleh $42 \%$ mahasiswa. Ammeter sebetulnya nama lain dari amperemeter yang merupakan alat ukur kuat arus listrik. Soal nomor 10 yang hanya mampu dijawab oleh 82 orang dari 195 orang mahasiswa mengindikasikan perlunya penelitian lebih lanjut mengenai masih terdapat kekeliruan mahasiswa dalam mengidentifikasi alat ukur kuat arus listrik atau mungkin saja para mahasiswa belum memperoleh informasi bahwa ammeter merupakan nama lain dari amperemeter yang termasuk alat untuk mengukur kuat arus listrik.

Indikator ketiga mengenai susunan rangkaian juga terdiri dari dua buah butir soal (soal nomor 13 dan soal nomor 14). Soal nomor 13 menanyakan tentang apakah rangkaian seri merupakan rangkaian yang tersusun sejajar, dan soal nomor 14 menanyakan tentang apakah rangkaian paralel tersusun berurutan. Soal nomor 13 menjadi soal tersulit dari keseluruhan 40 butir soal dengan persentase $12 \%$ dari 195 orang mahasiswa yang mampu menjawab dengan benar sementara soal nomor 14 hanya mampu dijawab dengan benar oleh 104 orang (53\%) mahasiswa. Soal nomor 13 dan nomor 14 sebenarnya soal yang saling bertolak belakang. Rangkaian seri merupakan rangkaian yang tersusun berurutan.

Karakteristik utama rangkaian seri adalah apabila salah satu beban (bisa dalam bentuk lampu atau hambatan) dicabut, terputus atau korslet, maka tidak akan ada arus yang melewati rangkaian itu. Oleh karena itu rangkaian seri disebut sebagai rangkaian yang tersusun berurutan yang artinya arus listrik hanya melalui satu rangkaian saja. Rangkaian paralel merupakan kebalikan daripada rangkaian seri di mana rangkaian hambatan atau rangkaian lampu tersusun sejajar. Artinya apabila salah satu beban (hambatan atau lampu) terputus, lampu atau hambatan yang lain masih dapat dialiri arus listrik sehingga lampu yang lain tetap akan terus menyala. Di sinilah pentingnya 
pemahaman konsep tentang rangkaian seri dan rangkaian paralel sebagaimana pemahaman konsep-konsep IPA sangat penting dimiliki oleh masing-masing peserta didik (Nooritasari, Rahmadiyah, \& Kusairi, 2019; Suryani, Rusilowati, \& Wardono, 2016; Suseno, \& Setiawan, 2013). Mahasiswa tentu akan mampu mengenali karakteristik rangkaian seri maupun rangkaian paralel ketika mahasiswa sudah paham konsep yang ada pada rangkaian seri dan rangkaian paralel.

Indikator keempat tentang karakteristik rangkaian berdasarkan arus listrik yang terdiri dari 14 butir soal yang secara keseluruhan mampu dijawab dengan benar oleh $67 \%$ mahasiswa. Butir soal nomor 18 yang menanyakan tentang apakah arus listrik bercabang/tidak bercabang pada rangkaian paralel merupakan butir soal termudah dari semua butir soal pada indikator karakteristik rangkaian berdasarkan arus listrik. Butir soal tersulit pada indikator keempat ini adalah nomor 28 yang menanyakan tentang dua buah lampu listrik identik (memiliki karakteristik beban atau hambatan yang sama besar) dirangkai secara paralel, mahasiswa menentukan apakah kuat arus listrik yang melalui masing-masing lampu apakah sama atau berbeda. Sebanyak 73\% atau 143 orang mahasiswa salah menjawab untuk soal nomor 28 ini. Hal ini dimungkinkan karena para mahasiswa meyakini bahwa apabila pada rangkaian paralel, setiap arus yang melalui percabangan nilainya selalu berbeda-beda. Kuat arus yang melalui percabangan bervariasi sesuai dengan besarnya beban atau hambatan di masing-masing percabangan. Semakin besar hambatan atau beban pada masing-masing percabangan, semakin kecil kuat arus listrik yang melalui percabangan itu. Apabila besar hambatan atau beban pada masing-masing percabangan nilainya sama, maka dapat dipastikan kuat arus listrik yang melalui masing-masing percabangan itu besarnya sama.

Rangkaian seri dan rangkaian paralel memiliki karakteristik berdasarkan tegangan yang dimiliki oleh masing-masing rangkaian. Besar tegangan pada masing-masing hambatan yang dirangkai seri bervariasi sesuai dengan besar hambatannya. Artinya semakin besar hambatan listrik maka semakin besar pula beda potensial antara kedua hambatan itu. Sebaliknya pada rangkaian paralel di mana masing-masing hambatan mendapatkan tegangan listrik yang besarnya sama dengan besar tegangan sumber. Berdasarkan indikator kelima yang terdiri dari 10 butir soal diketahui bahwa hanya $61 \%$ mahasiswa mampu menjawab dengan benar. Butir soal tersulit pada indikator kelima adalah butir soal nomor 35 yang menanyakan tentang "Dua buah baterai @1,5 volt dirangkai secara paralel maka tegangan total adalah 3 volt". Seharusnya mahasiswa memilih jawaban "salah" agar mendapat jawaban benar (kontradiksi). Namun sebanyak $68 \%$ mahasiswa kurang memahami konsep rangkaian batreai sehingga memberikan jawaban yang keliru. Berapapun jumlah baterai dengan tegangan 1,5 volt yang diparalelkan akan tetap menghasilkan tegangan yang sama dengan 1,5 volt. Besar 
tegangan pada baterai identik yang diparalelkan akan tetap sama dengan tegangan semula namun semakin diparalelkan, daya tahan baterai akan bisa dipakai untuk waktu yang lama. Butir soal termudah pada indikator kelima adalah soal nomor 20 di mana hampir sebagian besar (84\%) mahasiswa mampu menjawab dengan benar berkaitan dengan karakteristik rangkaian seri dan rangkaian paralel berdasarkan beda potensial atau tegangannya.

Berdasarkan pada Gambar 1 indikator keenam dapat diketahui secara umum bahwa kemampuan mahasiswa dalam membedakan rangkaian seri dan rangkaian paralel dilihat dari daya yang didisipasikan dapat dikatakan tidak berbeda secara signifikan. Hal ini dapat dilihat dari persentase mahasiswa yang mampu menjawab dengan benar adalah $52 \%$ dan yang tidak mampu menjawab dengan benar adalah $48 \%$. Daya listrik akan didisipasikan lebih besar ketika hambatan semakin kecil. Karakteristik suatu rangkaian dimana semakin diparalelkan suatu rangkaian hambatan, maka semakin kecil hambatan pengganti pada rangkaian yang mengakibatkan daya listrik yang dikonsumsi akan semakin besar. Oleh karena itu, pada soal nomor 38 "daya listrik yang dihabiskan oleh lampu yang dirangkai seri lebih kecil dari daya listrik yang dihabiskan oleh lampu yang dirangkai secara Paralel" merupakan pernyataan yang benar karena pada rangkaian seri, hambatan lampu semakin besar sehingga daya yang digunakan menjadi lebih kecil.

Secara keseluruhan dari keenam indikator dapat diketahui bahwa sebagian besar persentase kemampuan mahasiswa dalam membedakan rangkaian seri dan rangkaian paralel berada di atas 50\%, dan berdasarkan pada Tabel 2 dianggap bahwa profil kemampuan calon guru sekolah dasar dalam membedakan rangkaian seri dan rangkaian paralel berada pada kategori cukup

\section{SIMPULAN}

Simpulan penelitian ini menunjukkan bahwa $72 \%$ calon guru sekolah dasar mampu menjawab benar pada karakteristik rangkaian dilihat dari besaran satuan rangkaian listrik, $64 \%$ pada karakteristik alat ukur listrik, 33\% pada susunan rangkaian listrik, 67\% pada karakteristik rangkaian berdasarkan arus listrik, 61\% pada karakteristik rangkaian berdasarkan beda potensial atau tegangan listrik, serta $52 \%$ pada karakteristik rangkaian berdasarkan daya listrik. Secara keseluruhan, 63\% mahasiswa calon guru sekolah dasar mampu membedakan rangkaian seri dan rangkaian paralel sesuai dengan karakteristik pada masing-masing rangkaian. Berdasarkan hasil penelitian ini diketahui bahwa profil kemampuan mahasiswa dalam membedakan rangkaian listrik seri atau paralel berada pada kategori cukup. 


\section{DAFTAR PUSTAKA}

Afriki, Anggari, A. S., Wulan, D. R., Darmawanti, H., Puspitawati, N., \& Hendriyeti, S. 2015. Buku Tematik Terpadu Kurikulum 2013: Tema 3 Tokoh dan Penemuan. Jakarta: Kementerian Pendidikan dan Kebudayaan.

Desstya, A. 2014. Kedudukan dan Aplikasi Pendidikan Sains di Sekolah Dasar. Profesi Pendidikan Dasar, 1(2), 193-200.

Erfan, M., Widodo, A., Umar, U., Radiusman, R., \& Ratu, T. 2020. Pengembangan Game Edukasi "Kata Fisika" Berbasis Android Untuk Anak Sekolah Dasar Pada Materi Konsep Gaya. Lectura: Jurnal Pendidikan, 11(1), 31-46.

Fajari, L. E. W., Joharman, J., \& Salimi, M. 2018. Application of Natural Environment Approaches to Improve Science Process Skills in Elementary School Students. Social, Humanities, and Educational Studies (SHEs): Conference Series, 1(1). https://doi.org/10.20961/shes.v1i1.23584

Hakim, I. N. 2014. Pembelajaran Tematik-Integratif di SD/MI dalam Kurikulum 2013. INSANIA: Jurnal Pemikiran Alternatif Kependidikan, 19(1), 46-59. https://doi.org/10.24090/insania.v19i1.463

Khoeriyah, N., \& Mawardi, M. 2018. Penerapan Desain Pembelajaran Tematik Integratif Alternatif Berbasis Kearifan Lokal untuk Meningkatkan Hasil dan Kebermaknaan Belajar. Mimbar Sekolah Dasar, 5(2), 63. https://doi.org/10.17509/mimbarsd.v5i2.11444

Khishfe, R. 2012. Relationship Between Nature of Science Understandings and Argumentation Skills: A Role For Counterargument And Contextual Factors. Journal of Research in Science Teaching, 49(4), 489-514. https://doi.org/10.1002/tea.21012

Manurung, S. R., \& Sinambela, M. 2018. Perangkat Pembelajaran IPA Berbentuk LKS Berbasis Laboratorium. INPAFI (Inovasi Pembelajaran Fisika), 6(1). https://doi.org/10.24114/inpafi.v6i1.9496

Mawardi, M. 2014. Pemberlakuan Kurikulum SD/MI tahun 2013 dan Implikasinya Terhadap Upaya Memperbaiki Proses Pembelajaran Melalui PTK. Scholaria: Jurnal $\begin{array}{llll}\text { Pendidikan Dan } & \text { Kebudayaan, }\end{array}$ https://doi.org/10.24246/i.scholaria.2014.v4.i3.p107-121

Nurrahmawati, Y., Supeno, \& Prihandono, T. 2018. Prakonsepsi Siswa SMK Tentang Rangkaian Listrik Sederhana dalam Pembelajaran Fisika. Prosiding Seminar Nasional Pendidikan Fisika 2018 "Implementasi Pendidikan Karakter Dan IPTEK Untuk Generasi Millenial Indonesia Dalam Menuju SDGs 2030“, 241-246.

Nooritasari, D. D., Rahmadiyah, M., \& Kusairi, S. 2019. The Comparison of Conceptual Understanding Between Secondary School Students and Pre-Service Physics Teacher In Direct Current Electric Circuit. Jurnal Pendidikan Fisika Indonesia, 15(2), 80-86.

Ramdhani, S., \& Yuliastri, N. A. 2018. Model Pembelajaran Tematik Integratif untuk Membentuk Karakter Jujur Anak Usia 5-6 Tahun. JURNAL PELITA PAUD, 2(2), 149-150. https://doi.org/10.33222/pelitapaud.v2i2.226 
Sudarmadji, S. 2013. Penerapan Metode Eksperimen untuk Meningkatkan Hasil Belajar Siswa Kelas V SDN Manukan Kulon Surabaya. Jurnal Penelitian Pendidikan Guru Sekolah Dasar, 1(1), 1-6.

Suryani, E., Rusilowati, A., \& Wardono, W. 2016. Analisis Pemahaman Konsep IPA Siswa SD Menggunakan Two-Tier Test melalui Pembelajaran Konflik Kognitif. Journal of Primary Education, 5(1), 56-65. https://doi.org/10.15294/JPE.V5I1.12893

Suseno, N., \& Setiawan, A. 2013. Pengembangan Model Pembelajaran Inkuiri Menggunakan Analogi Pada Konsep Rangkaian Listrik Seri dan Paralel. Jurnal Pendidikan dan Pembelajaran (JPP), 19(2), 204-211.

Weisberg, D. S., Hopkins, E. J., \& Taylor, J. C. V. 2018. People's Explanatory Preferences For Scientific Phenomena. Cognitive Research: Principles and Implications, 3(1), 44. https://doi.org/10.1186/s41235-018-0135-2 